\title{
The effects of peritoneal dialysis on QT interval in ESRD patients
}

\author{
Wenjing Zhang, Yu Liang, Jia LV, Yan Li and Jiping Sun* (1)
}

\begin{abstract}
Background: Patients with chronic kidney disease (CKD) are at a high risk of fatal arrhythmias. The extended corrected QT (QTc) interval is a hallmark of ventricular arrhythmias and sudden cardiac death. Previous studies have shown that QT interval and QTc are prolonged with the decline in renal function. However, there were no available results for patients with peritoneal dialysis (PD). In this study, we examined changes in QT interval and QTc in patients with end-stage renal disease (ESRD) who underwent peritoneal dialysis.

Methods: A total of 66 ESRD patients who received PD, including 50 males and 16 females, with an average age of $43.56 \pm 15.15$ years, were enrolled. The follow-up lasted 1 year. The demographics and the etiology of patients were recorded. QTc and clinical/biochemical indexes before dialysis and at 6 and 12 months were determined and analyzed. Dialysis adequacy and peritoneal transport function were assessed in each patient. Analysis of variance (ANOVA), least significant difference (LSD) or Tamhane's T2, Paired T-test, Chi-square test, multiple linear regression analysis, and Pearson correlation coefficient were used to analyze the data. $P<0.05$ was considered as statistically significant.
\end{abstract}

Results: With reference to etiology, 37 patients (56.06\%) had chronic nephritis, and 11 (16.67\%) had diabetic nephropathy. Most of the peritoneal transport functions were low average transport $(25,37.88 \%)$, while the least were high transport (2,3.03\%).During the follow-up period, all patients had adequate peritoneal dialysis. Compared with a baseline before dialysis, anemia, low albumin, blood pressure, blood urea nitrogen, creatinine, uric acid, potassium, calcium, phosphorus, and parathyroid hormone improved after 6 and 12 months, while the residual renal function gradually decreased during the follow-up. The mean QTc of all patients was stable during the follow-up period. According to gender, the QTc in males and female patients were similar. Before PD, diastolic blood pressure, calcium concentration, and hemoglobin level were negatively correlated with QTc in end-stage renal disease patients; After $\mathrm{PD}$, the observed clinical indexes were no longer relevant to QTc.

Conclusion: Unlike hemodialysis-induced QTc prolongation, PD did not increase the patient's QT interval and QTc interval, which suggested that myocardial electrical activity might be more stable in patients with adequate peritoneal dialysis.

Keywords: Peritoneal Dialysis, QT interval, Corrected QT interval (QTc)

\section{Background}

Chronic kidney disease (CKD) is a global public health problem with an estimated prevalence of $11-13 \%$ [1], and one of the leading causes of death. CKD patients

*Correspondence: jipingsundwy@126.com

Department of Nephrology, The First Affiliated Hospital of Xi'an Jiaotong

University, 277 West Yanta Road, Xi'an 710061, Shannxi, China have an increased risk of developing life-threatening cardiovascular complications, including ventricular arrhythmias and sudden cardiac death. For example, cardiovascular disease (CVD) mortality is 30 times higher in patients undergoing dialysis than in the general population [2]. According to the USA National Institutes of Health, National Institute of Diabetes and Digestive and Kidney Disease, in 2020, approximately 
$55.2 \%$ of patients undergoing dialysis were associated with CVD, and $44.2 \%$ with cardiac arrest or arrhythmia [3].

QT interval represents the duration of ventricular depolarization and repolarization, and it is closely related to heart rate. The QT interval shortens with accelerating heart rate in normal people. The heart rate is used for correcting the QT interval: corrected QT interval [QTc, QTc $=$ QT $/(\mathrm{RR}$ interval in seconds $)$ ] [1]. A prolonged QTc interval is defined as QTc greater than $440 \mathrm{~ms}$ in males and QTc greater than $460 \mathrm{~ms}$ in females [4]. Prolonged QTc interval is found in $12.9 \%$ of the general population and in $20.5 \%$ of CKD patients [5]. Also, the QTc interval increases by an average of $2.9 \mathrm{~ms}$ for each milligram increase in serum creatinine [6]. Current studies have shown that the prolongation of QT interval and QTc may predict malignant ventricular arrhythmia and sudden cardiac death [7, 8]. Moreover, studies [9-11] have also proved that QT interval and QTc are prolonged with the declination of renal function, especially in patients with maintenance hemodialysis, showing longer QT interval and QTc after dialysis than before dialysis. Yet, it remains unclear how QT interval and QTc change in patients undergoing maintenance peritoneal dialysis (PD). To the best of our knowledge, this study analyzed the changes of QT interval and QTc in PD patients for the first time.

\section{Methods}

\section{Study subjects}

This single-center, the retrospective study enrolled patients with PD treated at the first affiliated hospital of Xi'an Jiaotong University between January 1, 2018 and May 31, 2019. The inclusion criteria were: (1) age > 18 years old; (2) the cause of the disease was not limited. The exclusion criteria were: acute exacerbation of CKD; acute kidney injury; contraindications to peritoneal dialysis and incomplete data; died within one year; varied basic cardiac diseases, such as myocardial infarction, myocardial ischemia, cardiomyopathy, and cardiac dysfunction; varied arrhythmias, such as atrial, junction and ventricular arrhythmias, various conduction blocks, and pacemaker implantation; patients using drugs to prolong QT interval. All eligible patients had no indication of emergency dialysis.

The study was conducted in accordance with the principles of the Declaration of Helsinki, and the ethics committee approved the study protocol of The First Affiliated Hospital of Xi'an Jiaotong University. Because of the retrospective nature of the study, patient consent for inclusion was waived.

\section{Peritoneal dialysis scheme}

All patients underwent manual PD on the day of PD catheter insertion: $1.5 \%$ peritoneal fluid, $1000 \mathrm{ml}$ was injected each time and maintained for $1 \mathrm{~h}$; the total dialysis dose was $6000 \sim 8000 \mathrm{ml} / \mathrm{d}$. After 10 days, the dose per time was changed to $2000 \mathrm{ml}$ and maintained for $4 \mathrm{~h}$. The total dialysis dose was $6000 \sim 8000 \mathrm{ml} / \mathrm{d}$. After 1 month, a peritoneal equilibration test and $\mathrm{PD}$ adequacy were performed. According to the $\mathrm{D} / P$ value, the peritoneal transport function was divided into four types: low transport, low average transport, high average transport, and high transport. Adequacy was calculated using $\mathrm{Kt} / \mathrm{V}$ and $\mathrm{Ccr}$ (renal, peritoneal, and total). The PD prescriptions were adjusted according to the above results. After PD for 6 months and 1 year, the dialysis adequacy evaluations were performed again.

\section{Electrocardiograph}

The twelve-lead surface electrocardiogram (ECG) was performed at a speed of $25 \mathrm{~mm} / \mathrm{s}$ and a voltage of $10 \mathrm{~mm} /$ mv before dialysis, and after 6 and 12 months. ECG parameters included heart rate, QT interval, and QTc. The QT interval was measured in all leads of ECG, and the longest QT interval was accepted. The start of the QT interval was measured from the beginning of the QRS complex; the end of the QT interval was measured at the return of the TP baseline or when a $U$ wave was present at the nadir between the $\mathrm{T}$ wave and the $\mathrm{U}$ wave. The QT interval was measured by an investigator for each patient and was corrected according to heart rate using Bazett's formula: $Q T c=Q T / \sqrt{ } R R(m s)$, where QTc was the corrected value of the $\mathrm{QT}$ interval.

\section{Fellow up and clinical/biochemical indexes}

The follow-up time was 1 year. The demographics, clinical, biochemical indexes, and ECG parameters before dialysis were recorded. After 1 month, the peritoneal transport function was recorded. The clinical biochemical indexes (including blood pressure, hemoglobin, blood urea nitrogen, serum creatinine, uric acid, albumin, potassium, magnesium, sodium, chlorine, calcium, phosphorus, parathyroid hormone, carbon dioxide binding rate, and residual renal function), dialysis adequacy, ECG parameters (including heart rate, QT interval, and QTc) were performed at 6-months and 1 year. The residual renal function (RRF) was calculated using the combined 24-h urinary urea and creatinine clearance.

\section{Statistical method}

The data were presented as means \pm standard deviation for continuous variables. Analysis of variance (ANOVA) was used to test the difference in the mean sample during 
the follow-up time. The least significant difference (LSD) or Tamhane's T2 was further compared whether there was any significant difference between the two groups. Paired T-test was used between the two groups. Comparison of counting data was achieved by using the Chi-square test. Multiple linear regression analysis and Pearson correlation coefficient were used to recognize elements related to QTc interval. $P<0.05$ was considered to be statistically significant. Analyses were performed by employing SPSS (version 22) statistical software package.

\section{Results}

\section{Demographics and clinical and biochemical indexes} before dialysis

A total of 66 PD patients, including 50 males and 16 females, with an average age of $43.56 \pm 15.15$ years (males: $43.74 \pm 15.53$ years; females: $43.00 \pm 15.92$ years) were enrolled in the study. In terms of etiology, 37 patients $(56.06 \%)$ had chronic nephritis, 11 patients (16.67\%) had diabetic nephropathy, and 8 patients
(12.12\%) had IgA nephropathy (Fig. 1). The peritoneal transport test showed that 25 patients $(37.88 \%)$ had low average transport, 24 patients $(36.36 \%)$ had high average transport, 15 patients $(22.72 \%)$ had low transport, and 2 patients (3.03\%) had high transport (Fig. 2).

\section{Clinical and biochemical indexes during the follow-up period}

Systolic blood pressure, diastolic blood pressure, albumin, blood urea nitrogen, creatinine, uric acid, potassium, magnesium, chlorine, phosphorus, calcium, hemoglobin, and carbon dioxide binding rate after 6 months and 1 year were better than those before dialysis, while the blood sodium level was higher and the eGFR (estimated glomerular filtration rate) was lower (all $P<0.05)$ (Table $1 \mathrm{a}, \mathrm{b}$, Table $2 \mathrm{a}, \mathrm{b}$ ); all clinical and biochemical indexes were not statistically significant between 6 months and 12 months $(P>0.05)$, (Table $2 \mathrm{a}, \mathrm{b})$.

\section{etiology for all patients}

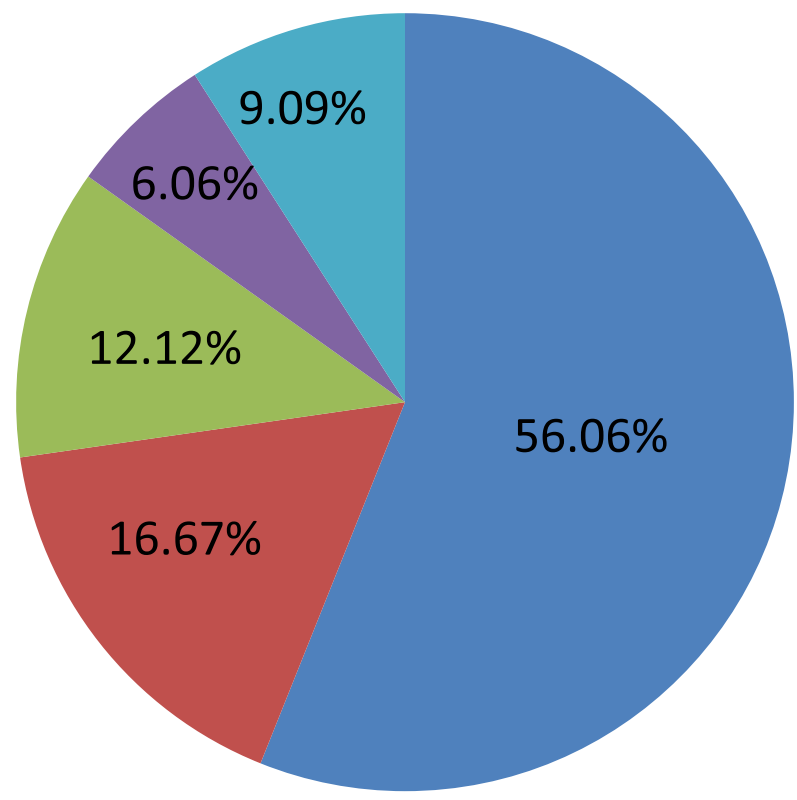

" chronic nephritis

IgA nephropathy n diabetic neohropathy

- Hypertensive nephropathy

other

Fig. 1 It showed the etiology for all patients. 37 patients (56.06\%) had chronic nephritis, 11 patients (16.67\%) had diabetic nephropathy, 8 patients (12.12\%) had IgA nephropathy, and 4 patients (6.06\%) had hypertensive nephropathy 


\section{peritoneal transport function}

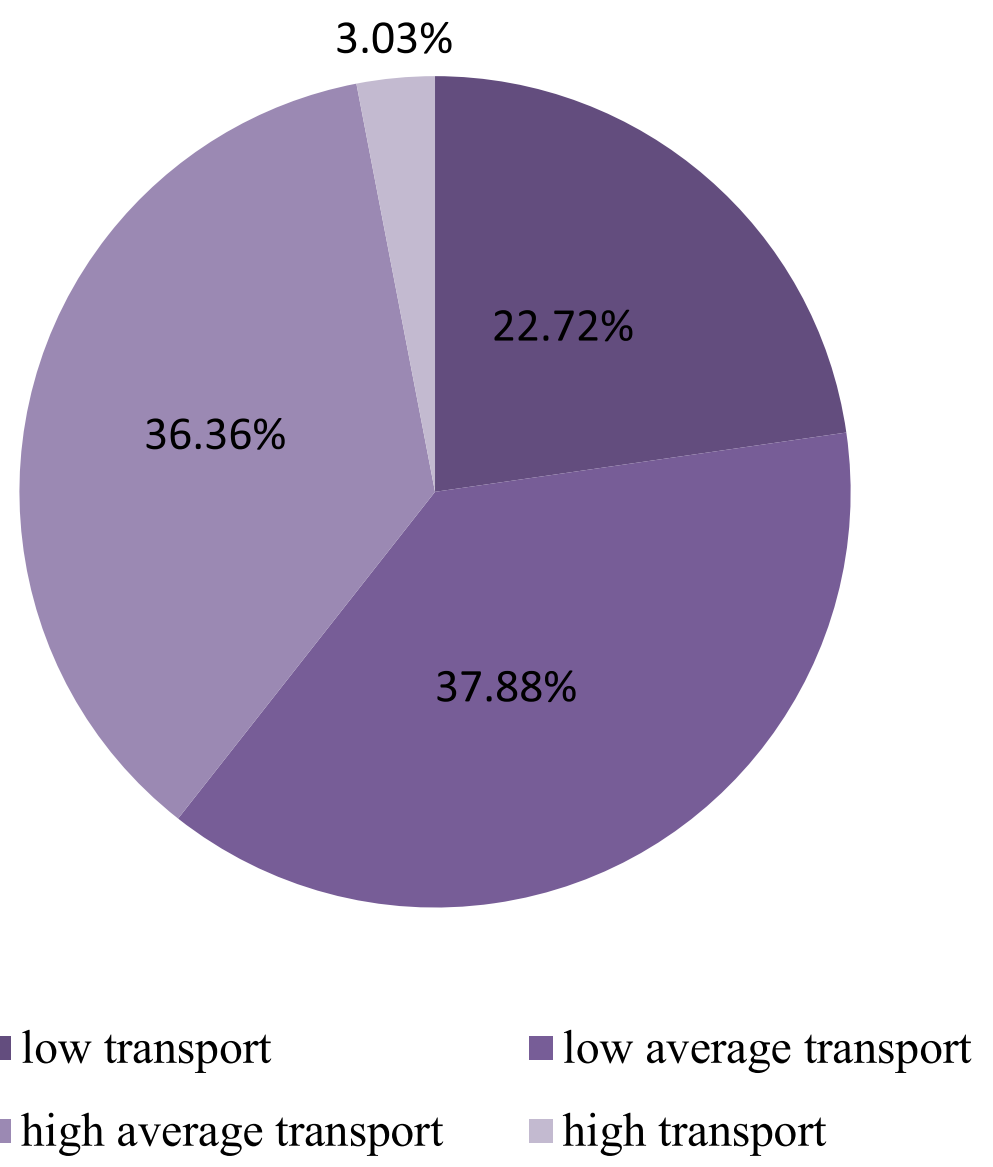

Fig. 2 It showed the peritoneal transport function for all patients. 25 patients (37.88\%) had low average transport function, 24 patients (36.36\%) had high average transport function, 15 patients (22.72\%) had low transport function, and 2 patients (3.03\%) had high transport function

\section{Dialysis adequacy during the follow-up period}

In terms of dialysis adequacy, the total $\mathrm{Kt} / \mathrm{v}$ were greater than 1.7 (at 6 months: $2.12 \pm 0.61$; at 1 year: $2.19 \pm 0.90$; $P=0.648$ ), and the total Ccr were higher than $50 \mathrm{~L}$ (at 6 months: $92.37 \pm 42.71 \mathrm{~L}$; at 1 year: $92.08 \pm 71.53 \mathrm{~L}$; $P=0.979$, Table 3 ), which indicated that patients had reached the standard of dialysis.

\section{Electrocardiograph parameters during the follow-up period}

During the whole follow-up period, the heart rate, QT interval, and QTc of all patients were similar, showing no statistically significant differences $(P>0.05$ respectively, Table 4 and Table 5$)$. According to gender, the QTc in males $(P=0.363)$ and female patients $(P=0.206)$ were similar (Table 6 and Table 5). Moreover, we found that the percentage of prolonged QTc in the population before and after PD were similar $(P>0.05$, Table 7$)$.

\section{Multiple linear regression analysis and Pearson correlation coefficient}

We evaluated SBP, DBP, ALB, eGFR, BUN, Scr, UA, potassium, magnesium, sodium, chlorine, phosphorus, calcium, PTH, hemoglobin, and carbon dioxide binding rate. And the "Enter" mode was used to determine which indexes were meaningful. Before PD, multiple linear regression analysis and Pearson correlation coefficient analysis showed that QTc was correlated with diastolic blood pressure, calcium, and hemoglobin, and the regression coefficients were $-0.870,-42.434$, and -0.483 , respectively (Table 8). Nevertheless, when the patients started PD, the observed clinical indexes no longer affected QTc. 
Table 1 Comparison of clinical biochemical indexes during follow-up period (Mean \pm SD)

\begin{tabular}{|c|c|c|c|c|c|c|c|c|}
\hline Items & $\begin{array}{l}\text { Systolic blood } \\
\text { pressure } \\
(\mathrm{mmHg})\end{array}$ & $\begin{array}{l}\text { Diastolic blood } \\
\text { pressure } \\
(\mathrm{mmHg})\end{array}$ & $\begin{array}{l}\text { Albumin } \\
(\mathrm{g} / \mathrm{L})\end{array}$ & $\begin{array}{l}\text { Blood urea } \\
\text { nitrogen } \\
\text { (mmol/L) }\end{array}$ & $\begin{array}{l}\text { Creatinine } \\
\text { (umol/L) }\end{array}$ & $\begin{array}{l}\text { Uric acid } \\
\text { (umol/L) }\end{array}$ & $\begin{array}{l}\text { Potassium } \\
(\mathrm{mmol} / \mathrm{L})\end{array}$ & $\begin{array}{l}\text { Magnesium } \\
(\mathrm{mmol} / \mathrm{L})\end{array}$ \\
\hline pre-PD & $148.64 \pm 20.13$ & $89.29 \pm 15.05$ & $33.82 \pm 5.11$ & $31.27 \pm 12.38$ & $925.25 \pm 343.76$ & $515.55 \pm 144.03$ & $4.59 \pm 0.83$ & $1.14 \pm 0.24$ \\
\hline 6 months & $131.71 \pm 20.14$ & $81.93 \pm 12.69$ & $38.03 \pm 5.16$ & $17.36 \pm 4.14$ & $774.30 \pm 274.32$ & $386.45 \pm 63.70$ & $4.19 \pm 0.66$ & $0.99 \pm 0.14$ \\
\hline 1 year & $134.77 \pm 18.58$ & $84.02 \pm 12.06$ & $37.07 \pm 4.80$ & $18.98 \pm 5.66$ & $888.60 \pm 319.12$ & $378.08 \pm 75.63$ & $4.11 \pm 0.65$ & $0.99 \pm 0.13$ \\
\hline Fvalue & 13.083 & 4.953 & 11.972 & 49.587 & 3.758 & 33.843 & 7.580 & 13.960 \\
\hline P & 0.000 & 0.008 & 0.000 & 0.000 & 0.025 & 0.000 & 0.001 & 0.000 \\
\hline \multicolumn{9}{|l|}{$b$} \\
\hline Items & $\begin{array}{l}\text { Sodium } \\
(\mathrm{mmol} / \mathrm{L})\end{array}$ & $\begin{array}{l}\text { Chlorine } \\
(\mathrm{mmol} / \mathrm{L})\end{array}$ & $\begin{array}{l}\text { Phosphorus } \\
\text { (mmol/L) }\end{array}$ & $\begin{array}{l}\text { Calcium } \\
(\mathrm{mmol} / \mathrm{L})\end{array}$ & $\begin{array}{l}\text { Parathyroid } \\
\text { hormone } \\
(\mathrm{pg} / \mathrm{ml})\end{array}$ & $\begin{array}{l}\text { Hemoglobin } \\
(\mathrm{g} / \mathrm{L})\end{array}$ & $\begin{array}{l}\text { Carbon diox- } \\
\text { ide binding } \\
\text { rate } \\
(\mathrm{mmol} / \mathrm{L})\end{array}$ & $\begin{array}{l}\text { eGFR } \\
\text { (ml/min) }\end{array}$ \\
\hline pre-PD & $138.82 \pm 4.44$ & $100.38 \pm 5.59$ & $2.11 \pm 0.60$ & $1.88 \pm 0.30$ & $314.65 \pm 208.71$ & $83.48 \pm 18.12$ & $18.42 \pm 3.92$ & $5.76 \pm 2.17$ \\
\hline 6 months & $141.88 \pm 3.12$ & $98.44 \pm 3.50$ & $1.35 \pm 0.38$ & $2.13 \pm 0.23$ & $327.63 \pm 219.86$ & $103.45 \pm 20.77$ & $22.95 \pm 3.20$ & $3.77 \pm 2.70$ \\
\hline 1 year & $141.39 \pm 3.25$ & $98.17 \pm 3.60$ & $1.49 \pm 0.44$ & $2.15 \pm 0.17$ & $362.42 \pm 240.12$ & $101.02 \pm 18.12$ & $23.72 \pm 5.05$ & $3.63 \pm 5.23$ \\
\hline Fvalue & 12.207 & 4.476 & 42.104 & 22.597 & 0.630 & 20.315 & 30.097 & 7.093 \\
\hline$P$ & 0.000 & 0.013 & 0.000 & 0.000 & 0.534 & 0.000 & 0.000 & 0.001 \\
\hline
\end{tabular}

Table 2 Comparison of clinical biochemical indexes between Groups during Follow-up Period

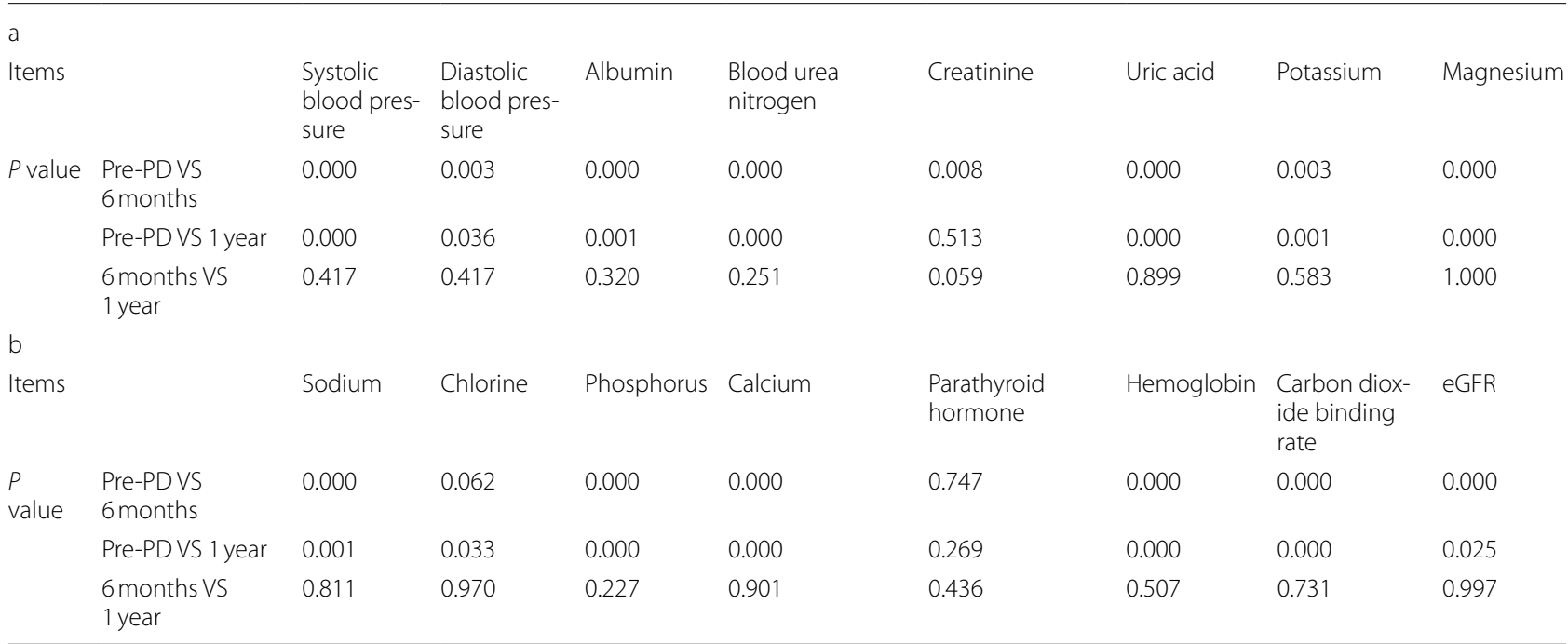

Table 3 Dialysis adequacy during the follow-up period (Mean \pm SD)

\begin{tabular}{lllllll}
\hline Items & PKt $/ \mathbf{v}$ & UKt $/ \mathbf{v}$ & TKt $/ \mathbf{v}$ & PCcr & UCcr & TCcr \\
\hline 6months & $1.43 \pm 0.39$ & $0.67 \pm 0.51$ & $2.12 \pm 0.61$ & $40.48 \pm 8.60$ & $51.90 \pm 43.17$ & $92.37 \pm 42.71$ \\
1 year & $1.50 \pm 0.41$ & $0.69 \pm 1.08$ & $2.19 \pm 0.90$ & $43.34 \pm 10.30$ & $48.74 \pm 77.38$ & $92.08 \pm 71.53$ \\
$t$ value & -1.187 & -0.205 & -0.819 & -1.049 & 0.587 & 0.058 \\
$P$ & 0.240 & 0.838 & 0.416 & 0.300 & 0.560 & 0.954 \\
\hline
\end{tabular}

Note: $P K t / v$ peritoneal urea clearance index; UKt/v renal urea clearance index; $T K t / v$ total urea removal index; $P C c r$ peritoneal $c r e a t i n i n e ~ c l e a r a n c e ~ r a t e ; ~ U C c r$ renal creatinine clearance rate; $T C \mathrm{cr}$ total creatinine clearance rate 
Table 4 Comparison of ECG parameters during the follow-up period (Mean \pm SD)

\begin{tabular}{llll}
\hline Items & Heart rate $(\mathbf{b p m})$ & QT interval $(\mathbf{m s})$ & QTc (ms) \\
\hline pre-PD & $81.90 \pm 12.69$ & $378.54 \pm 39.60$ & $413.49 \pm 29.95$ \\
6 months & $79.55 \pm 10.51$ & $390.57 \pm 54.33$ & $423.05 \pm 51.96$ \\
1 year & $80.12 \pm 13.48$ & $375.88 \pm 43.57$ & $409.29 \pm 32.32$ \\
F value & 0.534 & 1.365 & 1.592 \\
$P$ & 0.587 & 0.258 & 0.207 \\
\hline
\end{tabular}

Note: QTc corrected QT interval

\section{Discussion}

CKD is an increasing public health problem that can lead to coronary events [12] and reduce glomerular filtration rate (GFR), which is an independent risk factor of cardiovascular mortality caused by acute myocardial infarction, heart failure, thromboembolic disease, and sudden cardiac death (SCD). These events account for $26.5 \%$ of all-cause mortality and $64 \%$ of cardiac mortality in ESRD patients [13, 14].

QT interval represents the total time course of ven-

Table 5 Comparison of ECG indexes between groups during follow-up period

\begin{tabular}{|c|c|c|c|c|c|c|c|c|c|c|}
\hline \multirow[t]{2}{*}{ Items } & & \multicolumn{3}{|c|}{ Heart rate } & \multicolumn{3}{|c|}{ QT interval } & \multicolumn{3}{|l|}{ QTc } \\
\hline & & Total & Male & Female & Total & Male & Female & Total & Male & Female \\
\hline \multirow[t]{3}{*}{ Pvalue } & Pre-PD VS 6 months & 0.343 & 0.386 & 0.776 & 0.184 & 0.166 & 0.928 & 0.206 & 0.212 & 0.788 \\
\hline & Pre-PD VS 1 year & 0.443 & 0.252 & 0.481 & 0.754 & 0.794 & 0.137 & 0.553 & 0.946 & 0.128 \\
\hline & 6 months VS 1 year & 0.826 & 0.836 & 0.382 & 0.120 & 0.267 & 0.167 & 0.081 & 0.203 & 0.117 \\
\hline
\end{tabular}

Note: QTC corrected QT interval

Table 6 Comparison of ECG parameters in different genders during the follow-up period (Mean \pm SD)

\begin{tabular}{|c|c|c|c|c|c|c|}
\hline \multirow[t]{2}{*}{ Items } & \multicolumn{2}{|c|}{ Heart rate (bpm) } & \multicolumn{2}{|c|}{ QT interval (ms) } & \multicolumn{2}{|l|}{ QTc (ms) } \\
\hline & Male & Female & Male & Female & Male & Female \\
\hline pre-PD & $80.91 \pm 12.86$ & $84.81 \pm 12.11$ & $378.68 \pm 40.68$ & $378.13 \pm 37.54$ & $412.49 \pm 30.87$ & $416.44 \pm 27.79$ \\
\hline 6 months & $78.52 \pm 10.91$ & $83.33 \pm 8.31$ & $393.58 \pm 60.15$ & $379.56 \pm 21.97$ & $424.00 \pm 57.86$ & $419.56 \pm 20.65$ \\
\hline 1 year & $77.93 \pm 12.27$ & $88.27 \pm 15.25$ & $381.32 \pm 41.61$ & $355.64 \pm 46.74$ & $411.90 \pm 32.29$ & $399.55 \pm 31.99$ \\
\hline Fvalue & 0.744 & 0.437 & 1.047 & 1.428 & 1.023 & 1.658 \\
\hline$P$ & 0.477 & 0.650 & 0.354 & 0.254 & 0.363 & 0.206 \\
\hline
\end{tabular}

Note: QTC corrected QT interval

Table 7 Comparison of the percentage of prolonged QTC in different genders during follow-up period (\%)

\begin{tabular}{lll}
\hline Items & Male & Female \\
\hline Pre-PD & $18 \%(9 / 50)$ & $0 \%(0 / 16)$ \\
6 months & $22 \%(11 / 50)$ & $0 \%(0 / 16)$ \\
1 year & $20 \%(10 / 50)$ & $6.25 \%(1 / 16)$ \\
$X^{2}$ value & 0.250 & 2.043 \\
$P$ & 0.882 & 0.360 \\
\hline
\end{tabular}

tricular depolarization and repolarization. It varies with heart rate. The extended QTc interval is a hallmark of ventricular arrhythmias, SCD, and all-cause mortality [15]. Previous studies [9-11] have proved that with the declination of renal function, the QT interval and QTc are prolonged, especially in maintenance hemodialysis patients. Yet, changes in QT interval and QTc change in patients undergoing maintenance PD have not been explored.

Table 8 Influencing factors significantly correlated with QTc prolongation in ESRD (pre-PD)

\begin{tabular}{|c|c|c|c|c|c|c|}
\hline Characteristics & $\begin{array}{l}\text { correlation } \\
\text { coefficient (r) }\end{array}$ & $P$ values & $\begin{array}{l}\text { Regression } \\
\text { coefficient }\end{array}$ & $95 \%$ confidence intervals & T values & $P$ values \\
\hline diastolic blood pressure & -0.261 & 0.039 & -0.870 & -1.508 to 0.232 & -2.745 & 0.009 \\
\hline calcium concentration & -0.360 & 0.004 & -42.434 & -71.680 to -13.187 & -2.920 & 0.005 \\
\hline hemoglobin & -0.432 & 0.000 & -0.483 & -0.943 to 0.022 & -2.108 & 0.041 \\
\hline
\end{tabular}


In this study, we examined changes in QT interval and QTc in 66 ESRD patients who underwent peritoneal dialysis. Firstly, we observed the therapeutic effect on the patients. During the whole follow-up period, and especially after 6 and 12 months post dialysis, the dialysis adequacy was up to standard with a total $\mathrm{Kt} / \mathrm{v}>1.7$, and a total Ccr $>50$ L.Furthermore, the blood pressure control, anemia correction, malnutrition, calcium, phosphorus metabolism disorders, and acid-base balance disorders of patients showed significant improvement during PD compared to those before dialysis. At the same time, after 6 and 12 months, all clinical indexes were similar, and the differences were not statistically significant. Secondly, the changes of QT interval and QTc were observed in PD patients during dialysis. Liu et al [9] reported that the prolongation of QTc interval worsened with the decreased in renal function. Among patients with CKD stages 3, 4, 5 and patients who underwent hemodialysis, the proportion of patients with prolonged QTc and severely prolonged QTc were 32.43 and $1.4 \%, 40.23$ and $6.9 \%, 59.06$ and $10.1 \%, 64.31$ and $12.6 \%$, respectively [9]. Covic et al [10] and Malhis et al [11] observed an increase in QT interval and QTc in the pre- and post-hemodialysis period. In this study, however, QT interval and QTc were not prolonged when patients underwent PD treatment. Due to different gender, the definition of QT interval and QTc prolongation remained different. Therefore, the changes of QT interval and QTc before and after PD in male and female patients were compared, respectively. The obtained data showed that the QT interval and QTc were not prolonged before and after PD in both males and females and were similar after PD for 6 months and 12 months.

It remains unclear why the QT interval and QTc were significantly longer after hemodialysis but not after PD. The prolongation of QT interval was caused by increased inward current (i.e., the sodium or calcium channels) or a $\mathrm{K}^{+}$decreased outward current (i.e., potassium channel). The currents (Ikr and Iks) have a key role in myocardial repolarization. A prolonged action potential duration (APD) could lead to early changes after depolarization that is caused by inward depolarizing currents (L-type $\mathrm{Ca}^{2+}$ channels and $\mathrm{Na}^{+}-\mathrm{Ca}^{2+}$ exchange currents), inducing ventricular arrhythmias like torsade de pointes (TdP). ESRD patients are often accompanied by serious electrolyte acid-base balance disorder, such as hyperkalemia, hypocalcemia, metabolic acidosis, while potassium, calcium, magnesium and metabolic acidosis are important factors for electrical stability of the myocardium $[16,17]$. It is well known that hemodialysis can quickly stabilize electrolyte acid-base balance disorder in ESRD patients. The low concentrations of potassium and calcium in the dialysate can be quickly removed potassium in serum.
However, a large number of studies have shown a negative correlation between QTc interval change and calcium concentrations and potassium reduction during hemodialysis. Sherif et al [6] found that each $\mathrm{mmol} / \mathrm{L}$ increase of serum $\mathrm{K}+$ concentration might result in a $16 \mathrm{~ms}$ reduction of the QTc interval. Moreover, Alabd et al [18] have reported a negative correlation between decreased serum potassium and the change of QTc duration before and after dialysis. The higher decrease in the serum potassium has been associated with the longer QTc after dialysis. Also, Genovesi and colleagues [19] discovered that compared to patients who used dialysate with higher concentrations of potassium and calcium, patients who used dialysate with lower concentrations of potassium and calcium more had QTc intervals greater than $440 \mathrm{~ms}$.

The non-prolongation of QT interval and QTc in PD patients might be related to the following: firstly, compared with hemodialysis, PD has a lower ability to remove toxins per unit time, so most PD patients usually undergo continuous ambulatory peritoneal dialysis (CAPD). However, this method avoids drastic changes in the concentrations of various ions in the serum in a short time, and the concentration of various ions is in a relatively stable state. Secondly, peritoneal dialysate has two different calcium concentrations: physiological calcium and high calcium. Therefore, the appropriate calcium concentration dialysate is chosen for patients according to the patients' serum calcium concentrations. Although peritoneal dialysate is potassium-free dialysate, the patients have complete pre-dialysis education. They can be supplemented with potassium tablets and eat foods that are rich in potassium during PD to maintain the serum potassium in a stable state and avoid hypokalemia.

The heart's blood supply depends on diastolic perfusion, and the impact on myocardial blood supply is more direct if the diastolic blood pressure remains low. This effect is particularly prominent in patients with coronary artery stenosis and left ventricular hypertrophy. Low diastolic blood pressure can cause subendocardial myocardial ischemia that can significantly affect the ventricular repolarization process, resulting in QT and QTc prolongation. Renal anemia is a frequent complication in CKD patients. The prevalence of QT prolongation in patients with anemia is common $[20,21]$. The pathophysiological links between anemia and prolonged QT intervals are most probably hypoxia, autonomic dysfunction, and decreased myocardial oxygen supply. In addition, the impairment of delayed rectifier potassium channels and calcium channels might explain the changes in repolarization [22]. In our study, multiple linear regression analysis and Pearson correlation coefficient showed that diastolic blood pressure, 
calcium concentration and hemoglobin levels were influential factors for QTc prolongation before peritoneal dialysis that were negatively correlated with QTc ESRD patients, which is similar to the previous research results [19-21]. However, with the progression of PD, the symptoms and clinical indexes showed significant improvement, and our results showed that the clinical and biochemical indexes did not affect the QT interval and QTc anymore.

This study has a few limitations. This was a singlecenter retrospective study with a small sample. A multicenter study with a larger sample size with a longer follow-up is required to study the effects of PD on QT interval.

\section{Conclusion}

To sum up, we concluded that peritoneal dialysis did not increase the patient's QT interval and QTc. A myocardial electrical activity might be more stable in patients undergoing adequate PD.

\begin{abstract}
Abbreviations
CKD: Chronic Kidney Disease; PD : Peritoneal Dialysis; Kt/V: Urea clearance index; ECG: Electrocardiogram; ESRD: End-stage Renal Disease; SCD: Sudden Cardiac Death; CAPD: Continuous Ambulatory Peritoneal Dialysis; QTc: Corrected QT interval; CVD: Cardiovascular Disease; Ccr: Creatinine clearance rate; RRF: Residual Renal Function; eGFR: Estimated Glomerular Filtration Rate; TdP: Torsade de Pointes.
\end{abstract}

\begin{abstract}
Acknowledgements
I would like to express my warmest gratitude to Prof. Jiping Sun, my supervisor, for all the advice and suggestions that made this publication possible. Besides, I wish to thank my colleagues Yu Liang, Jia Lv and Yan Li, for their help with data collection and reference. What's more, I would like to thank all the patients for their support and for their interest in this research. Finally, I greatly appreciate my parents and husband for their support and endless love.
\end{abstract}

\section{Authors' contributions}

This study was proposed by Prof. JPS and discussed with Dr. WJZ to design this study. WJZ, YuL, JL and YanL jointly screened eligible patients and collected clinical data of all patients. All data were checked by JL and YanL. Statistics were completed by WJZ and YuL. The manuscript was written by WJZ and YuL, and was reviewed by Prof. JPS. All authors had read and approved the manuscript.

\section{Funding}

This work was supported by The National Natural Scicence Foundation of China (NO. 81700644) and The Shaanxi Social Development Science and Technology Research Project (NO. 2020SF-162). These two funding were applied by prof. Jiping Sun (corresponding author). We are very grateful to the funding body for their financial support, which enabled us to successfully pay the labor remuneration, language modification fee, layout fee and so on.

\section{Availability of data and materials}

Data are available from the corresponding authors on reasonable request.

\section{Declarations}

\section{Ethics approval and consent to participate}

This clinical study was a retrospective study. It only collected the clinical data of patients and did not interfere with the treatment of patients. The study was conducted in accordance with the principles of the Declaration of Helsinki, and the study protocol was approved by the ethics committee of The First Affiliated Hospital of Xi'an Jiaotong University. Because of the retrospective nature of the study, patient consent for inclusion was waived.

\section{Consent for publication}

Not Applicable.

\section{Competing interests}

ALL authors have declared that no competing interests.

Received: 19 December 2020 Accepted: 25 January 2022

Published online: 18 February 2022

\section{References}

1. Hill NR, Fatoba ST, Oke JL, Hirst JA, O'Callaghan CA, Lasserson DS, et al. Global prevalence of chronic kidney disease -a systematic review and Meta-analysis. PLoS One. 2016;11(7):e0158765.

2. Tonelli M, Wiebe N, Culleton B, House A, Rabbat C, Fok M, et al. Chronic kidney disease and mortality risk: a systematic review. J Am Soc Nephrol. 2006;17:2034-47.

3. National Institutes of Health, National Institute of Diabetes and Digestive and Kidney Diseases. (2021). The United States Renal Data System 2020 Annual Data Report. Retrieved from https://adr.usrds.org/2020.

4. Nie Y, Zou J, Liang Y, Shen B, Liu Z, Cao X, et al. Electrocardiographic Abnormalities and QTc Interval in Patients Undergoing Hemodialysis. PLoS One. 2016:11(5):e0155445.

5. Malik R, Waheed S, Parashara D, Perez J, Waheed S. Association of QT interval with mortality by kidney function: results from the National Health and nutrition examination survey (NHANES). Open Heart. 2017;4:e000683.

6. Sherif KA, Abo-Salem E, Panikkath $\mathrm{R}$, Nusrat M, Tuncel M. Cardiac repolarization abnormalities among patients with various stages of chronic kidney disease. Clin Cardiol. 2014;37:417-21.

7. Jervell A, Lange-Nielson F. Congenital deaf mutism, functional heart disease with prolongation of the QT interval, and sudden death. Am Heart J. 1957;54(1):59-68.

8. Schouten EG, Dekker JM, Meppelink P, Kok FJ, Vandenbroucke JP, Pool J. QT interval prolongation predicts cardiovascular mortality in an apparently healthy population. Circulation. 1991;84:1516-23.

9. Liu P, Han D, Sun X, Tan H, Wang Z, Liu C, et al. Prevalence and risk factors of acquired long QT syndrome in hospitalized patients with chronic kidney disease. J Investing Med. 2018;0:1-6. https://doi.org/10.1136/ jim-2018-000798.

10. Covic A, Diaconita M, Gusbeth-Tatomir P, Covic M, Botezan A, Ungureanu $\mathrm{G}$, et al. Hemodialysis increase QTc interval but not QTc dispersion in ESRD patients without manifest cardiac disease. Nephrol Dial Transplant. 2002;17(12):2170-7.

11. Malhis M, Al-Bitar S, Farhood S, Zaiat KA. Changes in QT intervals in patients with end-stage renal disease before and after hemodialysis. Saudi J Kidney Dis Transpl. 2010;21(3):460-5 PMID: 20427869.

12. Tonelli M, Muntner P, Lloyd A, Manns BJ, Klarenbach S, Pannu N, et al. Risk of coronary events in people with chronic kidney disease compared with those with diabetes: a population-level cohort study. Lancet. 2012;380:807-14.

13. Gansevoort RT, Correa-Rotter R, Hemmelgarn BR, Jafar TH, PharmSc HJLH, Mann JF, et al. Chronic kidney disease and cardiovascular risk: epidemiology, mechanisms, and prevention. Lancet. 2013;382:339-52.

14. Collins AJ, Foley RN, Chavers B, Gilbertson D, Herzog C, Johansen K, et al. United States renal data system 2011 annual data report: atlas of chronic kidney disease \& end-stage renal disease in the United States. Am J Kidney Dis. 2012;59:e1-420.

15. Zhang Y, Post WS, Dalal D, Blasco-Colmenares E, Tomaselli GF, Guallar E. QT-interval duration and mortality rate: results from the third National Health and nutrition examination survey. Arch Intern Med. 2011;171:1727-33.

16. Yetkin E, Ileri M, Tandogan I, Boran M, Yanik A, Hisar I, et al. Increased QT interval dispersion after hemodialysis: role of peridialytic electrolyte gradients. Angiology. 2000;51:499-504.

17. Antzelevitch C, Shimizu W, Yan GX, Sicouri S. Cellular basis for QT dispersion. J Electrocardiol. 1998;30(Suppl):168-75. 
18. Alabd MA, El-Hammady W, Shawky A, Nammas W, El-Tayeb M. QT interval and QT dispersion in patients undergoing hemodialysis: revisiting the old theory. Nephron Extra. 2011 Jan;1 (1):1-8.

19. Genovesi S, Dossi C, Viganò MR, Galbiati E, Prolo F, Stella A, et al. Electrolyte concentration during hemodialysis and QT interval prolongation in uraemic patients. Europace. 2008;10(6):771-7.

20. Stanojević M, Stankov S. Electrocardiographic changes in patients with chronic anemia. Srp Arh Celok Lek. 1998;126(11-12):461-6 PMID: 9921020

21. Cases-Amenós A, Martínez-Castelao A, Fort-Ros J, et al. Prevalence of anaemia and its clinical management in patients with stages 3-5 chronic kidney disease not on dialysis in Catalonia: MICENAS I study. Nefrologia. 2014;34(2):189-98. PMID: 24658193. https://doi.org/10.3265/Nefrologia. pre2013.Dec.12261

22. Detterich J, Noetzli L, Dorey F, Bar-Cohen Y, Harmatz P, Coates T, et al. Electrocardiographic consequences of cardiac iron overload in thalassemia major. Am J Hematol. 2012;87:139-44.

\section{Publisher's Note}

Springer Nature remains neutral with regard to jurisdictional claims in published maps and institutional affiliations.

- fast, convenient online submission

- thorough peer review by experienced researchers in your field

- rapid publication on acceptance

- support for research data, including large and complex data types

- gold Open Access which fosters wider collaboration and increased citations

- maximum visibility for your research: over 100M website views per year

At BMC, research is always in progress.

Learn more biomedcentral.com/submissions 